\title{
STUDI TRANSFORMATOR PADA GARDU INDUK PANAKKUKANG PERUSAHAAN LISTRIK NEGARA WILAYAH III
}

\author{
Abd.Hafid ${ }^{1}$, Debiana ${ }^{2}$, Muh. Yusuf ${ }^{3}$ \\ 1,2,3 Prodi Teknik Elektro Fakultas Teknik Universitas Muhammadiyah Makassar \\ e-mail: abd.hafid@unismuh.ac.idㄹ, debiana@ymail.com², myusuf@gmail.com ${ }^{3}$
}

\begin{abstract}
The operation failure of one of the main substation equipment, resulting in a number of end-users of electricity will be impaired. Maintenance on major equipment substation needs to be done to prevent damage and disruption as early as possible, and can extend the life of the equipment. Thus, the system of maintenance of equipment at a substation needs to be maintained and improved, especially on equipment - equipment that is essential for channel function and securing of a power interruption.
\end{abstract}

Intisari-Kegagalan operasi dari salah satu peralatan utama gardu induk, mengakibatkan sejumlah konsumen pemakai listrik akan mengalami gangguan. Pemeliharaan pada peralatan-peralatan utama gardu induk perlu dilakukan untuk mencegah kerusakan maupun gangguan sedini mungkin, serta dapat memperpanjang usia pemakaian peralatan. Dengan demikian, sistim pemeliharaan peralatan pada suatu gardu induk perlu dijaga dan ditingkatkan, utamanya pada peralatan peralatan yang berfungsi penting untuk menyalurkan dan mengamankan daya listrik dari gangguan.

Kata Kunci-Gardu Induk, Transformator,Oil Circuit Breaker.

\section{PENDAHULUAN}

Gardu induk adalah suatu stasiun penghubung yang menerima daya listrik dari pusat - pusat pembangkit melalui saluran transmisi untuk disalurkan ke gardu-gardu distribusi hingga ke pemakai. Sesuai dengan fungsi nya, maka gardu Induk dapat mentransformasikan daya listrik pada tegangan yang berbeda, mengatur penyaluran daya listrik kepada konsumen melalui gardu - gardu

distribusi, serta sebagai pusat pengatur tegangan dan pengatur beban.
Dari fungsi - fungsi tersebut, maka suatu gardu induk mempunyai peranan yang sangat penting untuk menyalurkan daya listrik kepada konsumen. Salah satu hal penting yang harus diperhatikan untuk peningkatan pelayanan secara kontinu kepada masyarakat, adalah masalah pemeliharaan peralatan. Gangguan gangguan yang terjadi pada operasi penyaluran energi listrik pada suatu gardu induk, sebagian besar disebabkan oleh cara pemeriksaan dan pemeliharaan peralatan yang kurang baik, sehingga resiko kecelakaan pada petugas serta kerusakan pada peralatan - peralatan tenaga listrik dapat terjadi. Oleh karena itu, cara perawatan pada peralatan tenaga listrik harus diperhatikan sebaik mungkin serta dituntut keahlian yang cukup bagi tenaga - tenaga personil yang menangani kegiatan pemeriksaan dan pemeliharaan, utamanya pada peralatan - peralatan listrik yang berfungsi penting untuk menyalurkan energi listrik kepada konsumen.

\section{TINJAUAN PUSTAKA}

Transformator daya

Trafo daya adalah suatu peralatan tenaga listrik yang berfungsi untuk menyalurkan daya listrik dari tegangan tinggi ke tegangan menengah atau sebaliknya. Pada trafo daya umumnya dilengkapi dengan suatu alat pengatur tegangan yaitu On Load Tap Changer (OLTC) artinya trafo tersebut dapat diubah-ubah tegangannya melalui suatu tap dan perubahan ini bisa dijalankan pada waktu trafo dalam keadaan berbeban. Umumnya trafo yang dilengkapi dengan OLTC adalah trafo-trafo dengan rating tegangan $30 \mathrm{KV}$ sampai $150 \mathrm{KV}$. Sebuah trafo daya terdiri dari bagian-bagian 
1) Bagian utama
1) Inti besi
2) Kumparan trafo
3) Minyak trafo
4) Isolator
5) Tangki konservator

2) Peralatan bantu
(a) Sistim pendingin
(b) Tap changer
(c) Sistim pernafasan breather )
(d) Indikator

3) Peralatan proteksi
(a) Rele Buchols
(b) Pengaman tekanan lebih
(c) Rele tekanan lebih
(d) Rele differensial
(e) Rele arus lebih
(f) Rele hubung tanah
(g) Rele termis ( rele pengaman suhu )
(h) Arrester
(i) Pemadam kebakaran

\section{Minyak trafo}

Sebagian besar trafo daya kumparankumparan dan intinya terendam dalam minyak, Minyak ini mempunyai sifat sebagai media pendingin dan isolasi untuk mencegah timbul nya kenaikan suhu dan hubung singkat

Didalam trafo daya terdapat dua komponen yang secara aktif membangkitkan energi panas, yaitu inti besi dan kumparan Bila energi panas tersebut tidak dapat disalurkan melalui suatu media sistim pendingin, akan mengakibatkan inti besi maupun kumparan akan mencapai suhu yang tinggi dan akan merusak nilai isolasinya, media sistim pendingin tersebut adalah minyak trafo, Disebabkan energi panas yang dibangkitkan dari inti besi maupun kumparan maka suhu minyak akan naik, hal ini akan mengakibatkan terjadinya perubahanperubahan pada minyak lagi pula dalam jangka waktu yang lama akan terbentuk berbagai pengotoran dan akan menurunkan tingkat isolasi minyak.

\section{Isolator trafo daya}

Hubungan antara kumparan trafo ke jaringan luar adalah dengan melalui isolator. Isolator dari trafo daya merupakan konduktor yang diselubungi porselin keramik yang berfungsi sebagai penyekat dengan tangki trafo.

ISSN 19 ハンールく

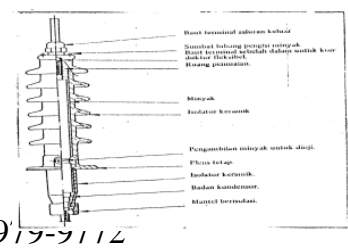

Gambar 2.3 Bagian-bagian isolator trafo Letak isolator trafo daya adalah seperti yang di tunjukkan pada nomor satu dari gambar berikut.

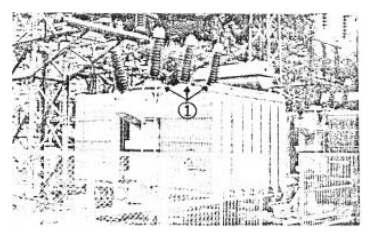

Gambar 2.4 isolator trafo daya

\section{Tangki konservator}

Pada umumnya bagian-bagian trafo yang terendam dalam minyak ditempatkan dalam tangki. Untuk menampung pemuaian minyak, maka tangki trafo daya dilengkapi dengan tangki konservator. Tangki konservator berhubungan langsung dengan rele Bucholz dan tangki trafo, serta memiliki ruang hampa udara, Tangki konservator ditunjukkan pada nomor dua dari gambar berikut.

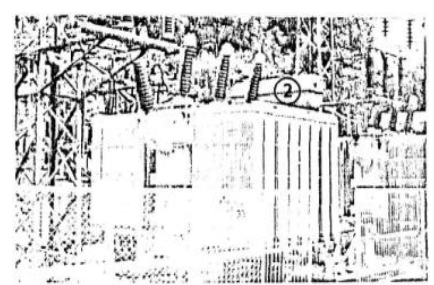

Gambar 2.5 Tangki konservator trafo

\section{Sistem Pendingin}

Pada inti besi dan kumparan - kumparan trafo akan timbul panas akibat rugi-rugi besi dan rugi -rugi tembaga. Bila panas tersebut mengakibatkan kenaikan suhu minyak yang melewati batas yang telah ditetapkan, maka akan merusak isolasi minyak dalam trafo dan untuk mengurangi kenaikan suhu yang tidak diizinkan tersebut, maka perlu dilengkapi alat pendingin untuk menyalurkan panas keluar dari dalam trafo. Pengaliran media sistim pendingin (berupa udara, gas, air atau minyak), adalah dengan cara alamiah dan cara paksaan (tekanan). Pada cara alamiah, pengaliran media sebagai akibat adanya perbedaan suhu dari media yang akan dialirkan untuk mempercepat perpindahan panas dari media tersebut ke udara luar, maka diperlukan bidang perpindahan panas dengan cara melengkapi trafo dengan sirip-sirip (radiator). Bila 
diinginkan penyaluran panas yang lebih cepat lagi, cara alamiah tersebut dapat dilengkapi dengan peralatan pompa-pompa sirkulasi dari media yang akan dikeluarkan dari dalam trafo daya.

\section{Tap changer}

Tap changer adalah alat perubah perbandingan trans formasi untuk mendapatkan tegangan operas! sekunder yang diinginkan dari tegangan jaringan primer. Tap changer yang hanya dapat beroperasi untuk memindahkan tap trafo dalam keadaan tanpa beban disebut Off Load Tap Changer yang di operasikan secara manual. Tap changer yang dapat beroperasi untuk memindahkan tap trafo dalam keadaan berbeban disebut On Load Tap Changer yang dapat dioperasikan secara manual dan otomatis.

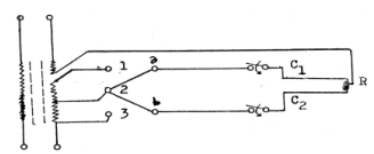

Gambar 2.6 diagram penyadapan On Load Pada operasi normal, saklar a dan b berada pada kedudukan penyadap nomor 2 , sedang $\mathrm{C}_{1}$, dan $\mathrm{C}_{2}$ tertutup. Jika penyadap akan dipindahkan, misalnya dari 2 ke 3 maka dilakukan operasi sebagai berikut :

1) $C_{2}$ dibuka $b$ dipindah ke posisi 3

2) $\mathrm{C}_{2}$ ditutup, arus sir kulasi mengalir namun besarnya dibatasi oleh reactor.

3) $\mathrm{C}_{2}$ dibuka a dipindahkan ke posisi 3 ,

4) $\mathrm{C}_{1}$ ditutup.

\section{Sistim pernafasan}

Pengaruh naik turunnya beban trafo maupun suhu udara luar, maka suhu minyak trafo akan terpengaruh oleh keadaan tersebut. Bila suhu minyak cukup tinggi melampaui batas yang diizinkan, maka minyak akan memuai dan mendesak udara diatas permukaan minyak keluar dari dalam tangki, dan sebaliknya apabila suhu minyak turun, maka minyak menyusut dan udara luar akan masuk kedalam tangki. Kedua proses tersebut dinamakan pernafasan trafo.

Akibat adanya pernafasan trafo tersebut, udara luar yang lembab disekitar trafo akan menurunkan nilai tegangan tembus (kekuatan dielektrik) minyak trafo, maka untuk hal tersebut pada ujung pipa penghubung udara luar di lengkapi dengan alat sistim pernafasan berupa tabung yang berisi zat silikasel. Dalam keadaan kering, zat silikasel akan berwarna biru. Warna biru berubah menjadi kuning bila zat silikasel menjadi lembab. Zat silikasel yang lembab dapat dikeringkan kembali dengan memanaskannya pada suhu antara $150^{\circ} \mathrm{C}$ hingga $200^{\circ} \mathrm{C}$.

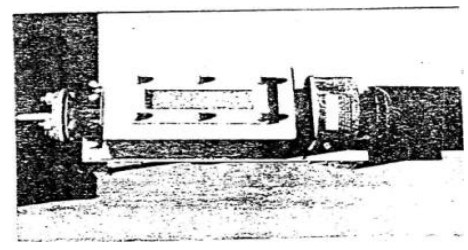

Gambar 2.7 Alat sistim pernafasan trafo daya

\section{METODOLOGI PENELITIAN}

\section{Waktu}

Pembuatan tugas akhir ini akan dilaksanakan enam bulan, mulai dari bulan Oktober 2013 sampai Maret 2014.

Tempat :

Penelitian ini dilakukan di Makassar

1) Tahapan penelitian Literatur

Penulisan dalam menyelesaikan tugas akhir ini, juga dengan melakukan studi buku-buku dan perpustakaan yang berkaitan dengan permasalahan serta gambar dari dokumen lainnya.

2) Pengumpulan data

Pengumpulan data yaitu dengan metode wawancara dan pengambilan data pada gardu induk Panakkukang, PLN sekrtor Tello, Kantor PLN Wilayah III, Kantor PLN cabang Makassar yang berkaitan dengan penyusunan tugas akhir ini.

3) Diskusi

Penulis melakukan diskusi dengan pihakpihak yang memahami permasalahan ini.

4) Penyusunan

Dalam pembuatan tugas akhir ini atau karya tulis diperlukan cara untuk menyusun pormulasi untuk mendapatkan hasil dari tugas akhir ini.

\section{ANALISIS HASIL PEMBAHASAN}

Pemeriksaan dan pemeliharaan peralatan tenaga listrik dari suatu gardu induk harus dilaksanakan untuk mencegah terjadinya kegagalan operasi rusaknya peralatan pada waktu dini dan kecelakaan yang mengancam keselamatan para petugas. Untuk melaksanakan hal ini, ada beberapa hal yang perlu diketahui, yakni:

1) Metode pemeliharaan

2) Jenis peralatan gardu induk 
3) Kegiatan pemeliharaan Metode pemeliharaan

Metode pemeliharaan yang harus dijalankan pada suatu gardu induk meliputi:

1) Metode rutin

2) Metode memecahkan masalah

1) Metode rutin

Pada metode ini dilakukan pengawasan dan pengecekan terhadap setiap peralatan pada waktu - waktu tertentu secara rutin. Meskipun peralatan - peralatan beroperasi secara normal, akan tetapi pada waktu waktu tertentu di perlukan pengawasan atau pengecekan agar peralatan tersebut selalu dapat berfungsi dengan balk serta memiliki tingkat efisiensi yang tinggi. Pada metode ini biasanya berupa kegiatan patroli harian.

\section{2) Metode memecahkan masalah}

Selain pengawasan dan pengecekan secara rutin terhadap peralatan-peralatan gardu induk yang dioperasikan secara normal, juga diperlukan pengawasan dan pengecekan dalam hal - hal yang menyimpang dari pembebanan yang di tentukan (normal). Hal ini perlu diperhatikan sebab daya tahan tiap peralatan tenaga listrik dirancang oleh pabrik pembuatnya untuk pembebanan pada batas - batas yang normal,

Hal-hal yang mungkin timbul sehingga mengakibatkan peralatan - peralatan gardu induk juga memerlukan pemeriksaan atau perawatan diluar waktu pemeliharaan rutin yakni:

1) Pembebanan diatas batas - batas yang diizinkan dalam waktu yang cukup lama sehingga menyebabkan timbulnya panas yang mengakibatkan ketahanan atau tingkat efisiensi dari suatu peralatan menurun.

2) Gangguan - gangguan hubung singkat yang menyebabkan pemutus tenaga membuka yang dapat merubah kedudukan kontak - kontak, sifat kimia dari minyak dan lain - lain. Untuk itu perlu pemeriksaan terhadap kondisi dari setiap peralatan yang terkena gangguan. Pada metode ini biasanya berupa kegiatan inspeksi biasa, yakni sebagian peralatan dibongkar dan dilepas untuk sementara dan peralatan dalam keadaan tidak beroperasi.

\section{Pemeliharaan kebersihan}

Pemeliharaan kebersihan trafo daya meliputi

1) Pembersihan isolator - isolator dan terminal -terminal dengan kain pembersih
2) Pembersihan badan trafo terutama pada bagian yang berminyak

3) Melakukan pengecatan baru pada seluruh badan trafo

4) Pembersihan kotoran dan rumput yang tumbuh di sekitar trafo

\section{Pemeliharaan pengaman}

Pemeliharaan alat pengaman pada trafo daya meliputi:

1) Pengaman Bucholz

2) Pengaman kebakaran

3) Pengaman tangki

4) Pengaman Bucholz

Pemeliharaan alat pengaman Bucholz antara lain :

(a) Melakukan penutupan kran pada kedua sisi Bucholz, membuka kran pembuang udara agar udara bisa masuk

(b) Mengosongkan minyak pada Bucholz sehingga dapat di lihat apakah peralatan untuk alarm dan pentripping dapat bekerja dengan baik

(c) Pengaman kebakaran

Alat pengaman kebakaran yang menggunakan gas hidrogen pemeliharaannya mengikuti petunjuk pabrik pembuatnya, sedang yang menggunakan air bertekanan, pemeliharaannya meliputi :

(a) Mengukur lamanya semprotan dan membandingkan ketika pertama kali digunakan

(b) Pemeriksaan air di dalam tangki

(c) Mencoba keandalan pengaman secara nyata

(d) Pengaman tangki

Pemeliharaan alat pengaman tangki trafo adalah dengan melakukan pemeriksaan tekanan gas pada indikator, serta merubah ke batas yang diizinkan bila penunjukan kelihatan tidak normal.

Batas - batas tahanan isolasi kumparan trafo

Menurut standar VDE ( standar Jerman ), minimum besar nya tahanan isolasi kumparan trafo pada suhu operasi bernilai :

$1 \mathrm{KV}=1 \mathrm{Mega}$ ohm

Besarnya kebocoran arus yang diizinkan adalah :

tiap $1 \mathrm{KV}=1 \mathrm{~mA}$

Adapun pemeliharaan trafo daya pada G.I Panakkukang, dilaksanakan dalam keadaan tidak beroperasi

Pemeliharaan trafo instrumen

Pemeliharaan trafo instrumen meliputi pemeliharaan trafo tegangan dan trafo arus. 


\section{Pemeliharaan trafo tegangan}

Pemeliharaan trafo tvegangan pada G.I Panakkukang adalah sekali dalam 1 tahun dilaksanakan secara rutin dan dalam keadaan tidak beroperasi. Bagian-bagian trafo yang diberi perawatan, meliputi :

1) Minyak, yakni melakukan pengetesan minyak yang harus memenuhi syarat syarat pengusahaan minyak trafo instrumen, pembersihan kaca indikator tinggi minyak serta pemeriksaan secara visuil batas ketinggian permukaan minyak yang diizinkan.

2) Tahanan isolasi, yakni dengan melakukan pengetesan pada isolasi kumparan dan harus memenuhi batas -batas harga tahanan isolasi trafo tegangan yaitu :

3) Antara sisi primer dan sisi sekunder ditanahkan, tahanan isolasi $(\mathrm{R}) \geq 50.000$ Mega ohm

(a) Antara sisi sekunder dengan tanah, $\mathrm{R} \geq$ $500 \mathrm{M}-\mathrm{ohm}$

(b) Isolator, meliputi pembersihan porselin dengan kain pembersih dan memberikan cat glyptal merah bila kelihatan adanya keretakan - keretakan

(c) Kerangka besi dudukan, yakni dengan memeriksa Jika terdapat perubahan dudukannya serta mengencangkan bautbaut yang kelihatan kendor atau longgar agar dudukannya tidak mengalami perubahan.

Pemeliharaan trafo arus

Pemeliharaan trafo arus pada gardu induk Panakkukang, adalah sekali dalam 1 tahun dilaksanakan secara rutin, dan dalam keadaan tidak beroperasi. Bagian - bagian trafo arus yang diberi perawatan, yaitu :

1) Minyak, yakni dengan melakukan pengetesan minyak dan harus memenuhi syarat-syarat pengusahaan minyak trafo instrumen, pembersihan kaca indikator tinggi minyak serta pemeriksaan secara visuil batas minyak yang diizinkan

2) Porselin, yakni dengan melakukan pembersihan dengan kain pembersih dan melakukan pengecatan bila di dapatkan keretakan-keretakan pada porsalinnya

3) Kerangka dudukan, yakni dengan memeriksa jika terdapat perubahan dudukannya dengan mengencangkan baut baut yang kelihatan kendor

4) Tahanan isolaei kumparan, yakni dengan melakukan pengetesan isolasi kumparannya dengan megger dan harus memenuhi syarat- syarat harga tahanan $(\mathrm{H})$ isolasi kumparan trafo arus yaitu :

(a) Antara lilitan primer dengan tanah, $\mathrm{R} \geq$ $500 \mathrm{M}$-ohm

(b) Antara-lilitan primer dan sekunder ditanahkan, $\mathrm{R} \geq 25.000$ Mega ohm

(c) Antara lilitan sekunder dengan tanah B $\geq 500$ Mega ohm

(d) Batas-batas (syarat-syarat) pengusahaan minyak trafo instrumen (pengukuran)

\section{Pemeliharaan trafo arus}

Pemeliharaan trafo arus pada gardu induk Panakkukang, adalah sekali dalam 1 tahun dilaksanakan secara rutin, dan dalam keadaan tidak beroperasi. Bagian - bagian trafo arus yang diberi perawatan, yaitu :

1) Minyak, yakni dengan melakukan pengetesan minyak dan harus memenuhi syarat-syarat pengusahaan minyak trafo instrumen, pembersihan kaca indikator tinggi minyak serta pemeriksaan secara visuil batas minyak yang diizinkan

2) Porselin, yakni dengan melakukan pembersihan dengan kain pembersih dan melakukan pengecatan bila di dapatkan keretakan-keretakan pada porsalinnya

3) Kerangka dudukan, yakni dengan memeriksa jika terdapat perubahan dudukannya dengan mengencangkan baut - baut yang kelihatan kendor

4) Tahanan isolaei kumparan, yakni dengan melakukan pengetesan isolasi kumparannya dengan megger dan harus memenuhi syarat-syarat harga tahanan $(\mathrm{H})$ isolasi kumparan trafo arus yaitu :

(a) Antara lilitan primer dengan tanah, $\mathrm{R} \geq$ $500 \mathrm{M}-\mathrm{ohm}$

(b) Antara-lilitan primer dan sekunder ditanahkan, $R \geq 25.000$ Mega ohm

(c) Antara lilitan sekunder dengan tanah B $\geq 500$ Mega ohm

5) Batas-batas (syarat-syarat) pengusahaan minyak trafo instrumen (pengukuran)

Batas - batas pengusahaan minyak trafo tegangan dan trafo arus, dapat dilihat pada tabel berikut :

$\begin{array}{ccccc}\text { Tegangan } & \mathrm{D} & \delta & \mathrm{Nmg} & \mathrm{G} \\ \text { nominal ( KV }) & \mathrm{KV} / & \% & \mathrm{KOH} & \%\end{array}$

$\mathrm{cm} \quad / \mathrm{g}$ 


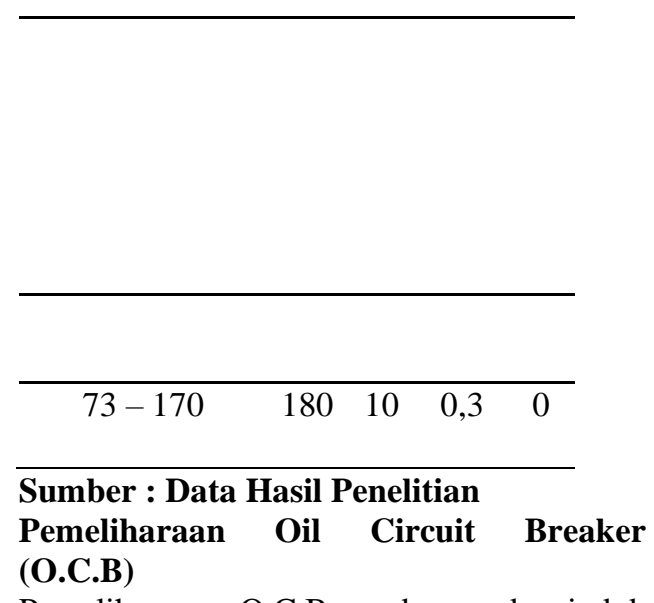

Pemeliharaan O.C.B pada gardu induk Panakkukang, di laksanakan sekali dalam waktu 6 bulan ( dua kali setahun ) dan dalam keadaan tidak beroperasi secara rutin. Akan tetapi, setiap. terjadi gangguan harus diadakan .pemeriksaan apakah O.C.B menutup dan membuka dengan balk ataukah tidak. Hasil - hasil pengawasan dan perbaikan dicatat dalam kartu pemeriksaan pemutus tenaga.

Adapun jumlah angka pemutusan (number of switching) dinyatakan dengan $\mathrm{n}$. $\mathrm{n}$ adalah menyatakan sekian kali C.B membuka (memutuskan arus). Pada saat terjadi pemutusan arus beban, $\mathrm{n}$ adalah 1 . Tetapi bila pembukaan C.B disebabkan oleh arus gangguan ( lebih besar dari pada arus nominal C.B ), maka $n \neq 1$ dan dinyatakan dengan n' (n ekivalen). Besarnya tergantung pada arus gangguan dan dinyatakan dengan rumus :

$$
\mathrm{n}^{\prime}=\mathrm{n}\left[\frac{I_{2}}{I_{1}}\right]^{1,5}
$$

keterangan :

$\mathrm{I}_{1}=$ Kapasitas arus pemutusan C.B (ampere)

$\mathrm{I}_{2}=$ Arus gangguan ( ampere )

$\mathrm{n}=$ Jumlah pemutusan $\mathrm{C} \gg \mathrm{B}$

$\mathrm{n}^{\prime}=$ Jumlah pemutusan arus gangguan C.B

1,5 = Kuadrat hasil pengetesan minyak $\mathrm{C} * \mathrm{~B}$ Arus $\mathrm{I}_{1}$, dapat diperoleh dari data

teknik C.B, Contoh suatu circuit breaker yang berkapasitas 1.500 MVA pada tegangan nominal $72,5 \mathrm{KV}$, maka :

$$
\mathrm{I}_{1}=\frac{1.500 \mathrm{MVA}}{\sqrt{3.72,5 \mathrm{KV}}}=12 \mathrm{KA}
$$

sedangkan arus $\mathrm{I}_{2}$ atau arus gangguan dapat diukur pada alat oscilloper turbograph di gardu induk. Bila telah di ketahui besarnya arus gangguan $\mathrm{I}_{2}$, maka untuk menentukan jumlah angka pemutusan

\begin{tabular}{|c|c|}
\hline$\frac{I_{2}}{I_{1}}$ & $\mathrm{~N}$ \\
\hline Pembukaan & 1 \\
\hline manipulasi & \\
\hline 0,1 & 5 \\
\hline 0,2 & 25 \\
\hline 0,3 & 50 \\
\hline 0,4 & 75 \\
\hline 0,5 & 105 \\
\hline 0,6 & 140 \\
\hline 0,7 & 175 \\
\hline 0,8 & 215 \\
\hline 0,9 & 255 \\
\hline 1 & 300 \\
\hline
\end{tabular}
C.B dapat dilihat pada tabel berikut.

\section{Sumber : Hasil Perhitungan}

\section{Pemeliharaan batere}

Pemeliharaan sel batere pada G.I Panakkukang, di laksanakan sekali dalam 1 minggu secara rutin dan dalam keadaan beroperasi. Pemeliharaan yang tidak benar terhadap tiap sel batere akan sangat berpengaruh terhadap sifat dari batere, yakni dapat mengakibatkan penurunan kapasitas sel batere, memperpendek usia .pemakaian, serta menimbulkan gangguan - gangguan pada setiap beban yang di layani. Bagian bagian dari batere yang diberi perawatan meliputi :

1) Sel batere. Tegangan setiap sel batere harus di sesuaikan dengan kapasitas, dan berat jenis dari batere dijaga agar tetap konstan

2) Ruangan batere, Ventilasi udara harus cukup terbuka agar terjadi sirkulasi udara sehingga suhu ruangan batere tetap normal

3) Cairan elektrolit, yakni dengan menjaga tinggi cairan elektrolit dalam sel batere sesuai dengan batas yang diizinkan 
Vertex Elektro, Vol. 01, No. 02, Tahun 2019

4) Sambungan batere. Hubungan dengan rectifier dan batere charger tidak boleh terputus, dan jika di dapatkan baut yang longgar maka harus dikencangkan kembali

\section{Pemeliharaan panel control}

Pemeliharaan semua panel kontrol yang terdapat pada gardu induk Panakkukang tidak memiliki jadwal tertentu. pembersihan kotoran - kotoran seperti debu atau zat - zat rang mengandung minyak dilaksanakan setiap saat. Apabila didapatkan indikator indikator atau alat instrumen yang tidak berfungsi, maka operator yang bertugas melakukan pencatatan pada buku laporan harian sambil melakukan perbaikan perbaikan seperlunya.

\section{PENUTUP}

\section{Kesimpulan}

Dari hasil peninjauan pada gardu induk Panakkukang di Makassar serta uraianuraian mengenai sistim pemeliharaannya, ternyata bahwa :

1) Sistim pemeliharaan peralatan utama gardu induk Panakkukang, khususnya pada trafo belum sesuai dengan ketentuan yang harus dijalankan yakni pemeriksaan secara rutin pada peralatan yang sedang beroperasi diluar jadwal pemeliharaan bulanan dan tahunan, dalam hal ini jadwal pemeliharaan harian belum dijalankan.

2) Kerusakan peralatan-peralatan utama pada gardu induk Panakkukang bukan disebabkan oleh cara pengoperasian yang salah, tetapi disebabkan oleh cara pemeliharaan yang kurang baik, dan hal ini bukan disebabkan adanya unsur kesengajaan namun disebabkan oleh kurangnya personil yang menangani masalah tersebut.

\section{Saran-saran}

1) Hendaknya pihak P.L.N Wilayah VIII membuatkan rencana kerja pemeliharaan harian pada gardu induk Panakkukang khususnya, dan seluruh gardu induk yang ada dalam wilayah kota madya Makassar pada umumnya.

2) Hendaknya pihak P.L.N Wilayah VIII dalam hal ini seksi gardu induk bagian pemeliharaan peralatan, menempatkan petugas yang khusus menangani kegiatan pemeriksaan dan pemeliharaan peralatan pada setiap gardu induk yang ada dalam wilayah kota madya Makassar.

\section{DAFTAR PUSTAKA}

Aris Munandar.A," Teknik Tenaga Listrik " jilid III., 2013

Aris Munandar.A," Teknik Tegangan Tinggi ." cetakan ke empat, Pradnya Paramita Jakarta 2013.

Abdul Kadir.Prof.Ir. " Transformator" jilid I. Gramedia Jakarta 2013.

J.E.C " Instruction For Maintenance Inspection Of Trans former " standard book, Osaka Transformer Co.Ltd Japan 2010.

Perusahaan Umum Listrik Negara, "Himpunan Buku Petunjuk Operasi Dan Pemeliharaan Peralatan Penyaluran Tenaga Listrik" Jakarta 2013.

Soedibyono. Ir. MUsc. " Gardu Induk " edisi I, Perusahaan Umum Listrik Negara, Jakarta 2013.

Weedy B.M, Si stem Tenaga Listrik " jilid III, South-hampton 2013. 